\title{
THE ESTIMATION OF FAT IN HOMOGENIZED MILK.
}

\author{
By H. DROOP RICHMOND, F.I.C. \\ (Read at the Meeting, May 2, 1906.)
}

Homogenized milk, or milk in which the fat is broken up into very small globules, not usually exceeding $0.001 \mathrm{~mm}$. in diameter, is now an article of commerce. It is obtained by forcing milk under a pressure of from 200 to 400 atmospheres through very small openings ; there are several machines made for this purpose, differing from each other chiefly in the method of formation of the small openings. The cream in homogenized milk no longer rises freely, but remains to a very great extent distributed throughout the whole volume.

The process is chiefly applied to sterilized milk, which is often required to stand for a long time before being used, and from which it is an undesirable thing for the cream to separate; but milk which has to stand-e.g., on refreshment-bar countersis also sometimes homogenized. It is therefore quite possible that some of the samples of milk taken under the Sale of Food and Drugs Act may be homogenized. As it appeared more than probable that the estimation of fat, especially by dry extraction processes, would be rendered more difficult by the fine state of division of the fat, I have made a few comparative experiments by different methods.

The methods chosen were those in common use by public analysts, together with the Kieselguhr method. In the Gottlieb and Werner-Schmid methods the 
original plan of taking an aliquot portion was not followed, but the whole of the fat was dissolved out by repeated extraction. The Adams method was carried out by extracting a blank coil into a flask tared against the flask in which the fat was weighed. In the other methods the flask was, after weighing, washed out with petroleum ether, and weighed again with any residue of substance not soluble in petroleum ether. Very slight residues were almost always obtained, but so small, if due care had been employed, that the percentage of fat was barely affected. The following are the results :

\begin{tabular}{|c|c|c|c|c|}
\hline $\begin{array}{c}\text { Gottlieb. } \\
3 \cdot 79\end{array}$ & $\begin{array}{c}\text { Kieselguhr. } \\
3.80\end{array}$ & $\begin{array}{c}\text { Werner-Schmid. } \\
3.81\end{array}$ & $\begin{array}{l}\text { Adams. } \\
3.58\end{array}$ & $\begin{array}{c}\text { Gerber. } \\
3 \cdot 78\end{array}$ \\
\hline $3 \cdot 70$ & $3 \cdot 70$ & $3 \cdot 74$ & $3 \cdot 52$ & $3 \cdot 70$ \\
\hline $3 \cdot 66$ & $3 \cdot 66$ & $3 \cdot 67$ & $3 \cdot 53$ & $3 \cdot 70$ \\
\hline $3 \cdot 46$ & $3 \cdot 46$ & $3 \cdot 45$ & $3 \cdot 32$ & $3 \cdot 47$ \\
\hline $3 \cdot 86$ & $3 \cdot 87$ & $3 \cdot 88$ & $3 \cdot 66$ & $3 \cdot 89$ \\
\hline $3 \cdot 93$ & $3 \cdot 94$ & $3 \cdot 98$ & $3 \cdot 81$ & $3 \cdot 95$ \\
\hline
\end{tabular}

It is seen that though the Werner-Schmid method has a tendency to be a trifle higher than the others, the first three methods are in almost perfect agreement, while the Adams method is always low. The Gerber method also gives good results with homogenized milk.

Microscopic examination shows that the fibres of the paper used for the Adams coils are very many times larger than the fat globules, while the diatoms of Kieselguhr have openings which are much smaller. Though the Adams coil provides sufficient surface to insure that the thickness of the film of milk solids is of the some order as the size of the fat globules in ordinary milk, and thereby exposes them to the solvent action of ether, it fails to do so when homogenized milk is extracted. The film is of sufficient thickness for some of the fat globules in homogenized milk to be completely surrounded with a layer of solids insoluble in ether. With kieselguhr there is a much larger surface, and the layer of milk solids is not thick enough to completely surround the globules.

The advent of homogenized milk renders it necessary to remove the Adams method from the position it has so long occupied as a standard method. In my laboratory it has for some time been discarded in favour of the Gottlieb method, which for ease and accuracy appears to be the best method we have, and I have little doubt that it will be in the future almost universally used.

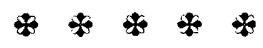

